Corrigendum

\title{
Corrigendum to "Nurse interrupted: Development of a realistic medication administration simulation for undergraduate nurses" [Nurse Educ. Today 35 (99), September 2015, 981-986]
}

\author{
${ }^{a}$ University of Technology Sydney, Faculty of Health, Building 10, 235 Jones Street, Broadway, NSW 2007, Australia \\ b John Hopkins University School of Nursing, United States \\ ${ }^{\mathrm{c}}$ University of Technology Sydney, Faculty of Health, PO Box 123, Broadway, NSW 2007, Australia \\ ${ }^{\mathrm{d}}$ Oxford Brookes University, Oxford, UK \\ ${ }^{\mathrm{e}}$ University of New England, NSW, Australia
}

Carolyn Hayes $^{\mathrm{a}, *}$, Tamara Power ${ }^{\mathrm{a}}$, Patricia M. Davidson ${ }^{\mathrm{b}}$, John Daly ${ }^{\mathrm{c}}$, Debra Jackson ${ }^{\mathrm{d}, \mathrm{e}}$

The authors regret that there is a typographical error in the Abstract section of this article.

The text should read: "Written reflections were completed and submitted over the following 2 weeks to extend the reflective learning process and review the impact of the experience from the student perspective".

The authors would like to apologise for any inconvenience caused.

DOI of original article: https://doi.org/10.1016/j.nedt.2015.07.002

* Corresponding author.

E-mail address: Carolyn.Hayes@uts.edu.au (C. Hayes).

https://doi.org/10.1016/j.nedt.2019.03.001 